\title{
Internal Model Control of a Domestic Microwave for Carbon Composite Curing
}

\author{
James E. Green, Member, IEEE, Betime Nuhiji, Karlis Zivtins, Matthew P. Bower, \\ Richard V. Grainger, Richard J. Day, and Richard J. Scaife
}

\begin{abstract}
This paper outlines the conversion of a domestic microwave oven for use in composite curing applications. It compares several strategies for temperature control. The converted oven has vacuum ports, connectors, and fiber optic thermocouple sensors. Experimental data are provided for each control strategy based on a $200 \mathrm{~mm} \times 200 \mathrm{~mm}$ eight-ply prepreg laminate. The degree of cure is established for the test samples by thermal analysis techniques. Multiphysics simulation is used to model the electromagnetic and heating effects in the system, and a common and inexpensive method of approximating the available microwave power is used. The low cost of the microwave components and the ease of conversion are desirable characteristics in this application.
\end{abstract}

Index Terms-Automatic control, composite materials, epoxy resins, microwave heating, temperature control.

\section{INTRODUCTION}

$\mathbf{M}$ ICROWAVE ovens have been used to cure carbon composite materials in research applications for a number of years. Microwave heating continues to generate interest due to the potential for faster, more energy-efficient heating for many industrial processes, including the curing of epoxies [1]. However, microwave heating still suffers from problems with heating uniformity. The use of polymer matrix composite materials has grown from $2 \%$ to $50 \%$ by weight in aerospace applications in the last 50 years and is expected to continue growing [2]. Laboratory-scale experiments have shown very promising reductions in processing time using microwave heating [3]. Boey and Lye [4] have modified an autoclave to include a scanning microwave source and have made laminates, as have Feher et al. [5]. Qiu and Hawley [6] have processed laminates and 3-D structures in a microwave setup.

Manuscript received December 21, 2016; revised February 3, 2017, March 10, 2017, and March 22, 2017; accepted March 22, 2017. This work was supported by the EPSRC via an Impact Acceleration Account. (Corresponding author: James E. Green.)

J. E. Green is with the Department of Electronic and Electrical Engineering, The University of Sheffield, Sheffield S1 4DE, U.K. (e-mail: j.e.green@sheffield.ac.uk).

B. Nuhiji and R. J. Scaife are with the Advanced Manufacturing Research Center with Boeing, The University of Sheffield, Rotherham S60 5TZ, U.K.

K. Zivtins is with Intertek, Bristol BS11 9DH, U.K.

M. P. Bower is with the Interdisciplinary Programs Office, The University of Sheffield, Sheffield S3 7HQ, U.K.

R. V. Grainger is with Rolls Royce Composite Technology and Applications Limited, East Cowes PO32 6LR, U.K.

R. J. Day is with the Advanced Composite Training and Development Center, Glyndŵr University Wrexham, Wrexham LL11 2AW, U.K.

Color versions of one or more of the figures in this paper are available online at http://ieeexplore.iee.org.

Digital Object Identifier 10.1109/TMTT.2017.2693145
Many microwave heating applications generate the necessary RF energy using one or more magnetrons, which are inexpensive compared to traveling-wave tubes and solidstate amplifiers. A notable exception is the variable-frequency commercial systems of Lambda Technologies. ${ }^{1}$ One problem in the control of magnetron-based heating is that a significant dead band exists in the RF output. There is minimum available output power, which is generally only approximately $50 \%$ of the rated power. Below this threshold, no power is available because the magnetron does not oscillate. This problem is often overcome in food preparation applications by heating for a short period of time at a moderate power, followed by a significant period of no heating to reduce the average power over the whole period. This is acceptable because the cooling thermal time constant of the food is often long compared to the heating time constant. Several composite systems have exothermic reactions in certain temperature ranges and are combustible in air, so a finer degree of control is desirable, especially when a swift heating rate is desired. One of the main costs of composite production in aerospace applications is related to the time taken to cure parts by standard methods in an autoclave. Interest in microwaves for curing composites is generally centered around the high temperature ramp rates available.

Microwaving is often considered as a kind of "volumetric heating." However, in lower-resistance media, such as carbon fibers, this is not usually the case as dominantly surface heating occurs due to skin depth considerations. Assume that the electrical conductivity of an example composite is uniform and dominated by the fibers. The dipole heating relies on the existence of a strong electric field. Electric fields do not penetrate good conductors well, so the dipole heating is restricted, in the case of the laminates in this paper, to the outer $3 \%$ or so of the sample. Joule heating relies on a current flowing in the fibers and the fibers having a nonnegligible resistance. To produce a current, an electric potential must exist between portions of the conductor where the current is expected to flow. As a result, only fibers near to the surface (where the electric field exists) should be expected to carry a current. Electrical power will be dissipated as heat in this region only. In the case of the results in this paper, only the outer $3 \%$ of the laminate is directly heated. The rest of the sample is not heated. However, it will get hot due to thermal conduction through the laminate from the

${ }^{1}$ Lambda Technologies Inc., Morrisville, NC 27560, USA. 
surface to the innermost parts. In carbon composites, this can often happen quickly since the thermal conductivity is usually reasonably good, even in the nonfiber direction(s). Both dipole heating and joule heating contribute to the overall heating to some extent. The relative contribution is dependent on the loss tangent of the epoxy and the resistivity of the fibers. Both the loss tangent and the resistivity are somewhat a state of cure and temperature dependent. The high temperature ramp rate compared to autoclaves exists despite epoxies not being very dielectrically active as a combination of the dipole and joule heating, caused by current induction in the fibers, heats the material efficiently via the $I^{2} R$ losses.

During a cure cycle, it is not necessary for the microwave applicator to heat up to the same extent as the autoclave casing. However, maintaining very large thermal gradients inside the oven presents nonuniform cooling problems. The thermal mass of an autoclave is high due to its robust construction, which is necessary to allow it to act as a pressure vessel. Pressurizing the autoclave allows the reduction of voids in the composite by compressing it as curing proceeds while using a high-viscosity resin. A common pressure is 8 atm with a further 1 atm derived from the vacuum system that surrounds each composite component. Low void content is desirable to optimize mechanical metrics of quality and therefore flight worthiness. A similar effect is created by encasing the composite in a vacuum bag inside a microwave oven and using the weight of the air pressing on the vacuum bag to consolidate the composite as it cures. This is "out-of-autoclave" processing and is not limited to microwave ovens. Out-of-autoclave processing is less effective at compressing the resin than the positive pressure system of the autoclave. Lower-viscosity resins are often used for out-of-autoclave processes.

A standard autoclave may reach a maximum heating rate of $5{ }^{\circ} \mathrm{C} / \mathrm{min}$ and take many hours to cool down. Many carbon composites can be heated and cooled orders of magnitude more quickly without any deleterious effects. Autoclaves are a capital investment for their owners and, because they are very expensive, space inside them is usually the bottleneck in production processes.

This paper investigates techniques to control a magnetronbased microwave heating process. We report a relatively inexpensive approach to laboratory-scale microwave heating using commonly available electronics systems. The objective is to compare several control algorithms to evaluate their suitability for minimizing the temperature ripple and overshoot in a magnetron-derived heating process, having the capability to develop high $d T / d t$ in modestly sized composite parts on the order of a vaccuum wavelength at $2.45 \mathrm{GHz}$.

In Section II, we review the use of domestic ovens in the composite curing literature. Section III describes the microwave modified in this work, including the hardware modification, the real-time software architecture, and control system design. Section IV describes an inexpensive static water heating-based approach to RF power estimation. Two modeling techniques to verify the water heating approach are also reported. Section V reports experimental results of curing carbon fiber laminates using different control strategies, including multiphysics modeling of the heating of the laminates. Section V also offers some explanation for the nonuniformity observed in conjunction with some extra experiments to verify this explanation. Section VI presents the thermal analysis results, and Section VII discusses some of the limitations, both of microwaving composites in general and of using domestic ovens in research applications.

\section{REVIEW OF DOMESTIC OVEN USE IN COMPOSITES RESEARCH}

Since a domestic microwave applicator supports multiple modes, it is not trivial to determine the electric field distribution in the cavity analytically. Coupled multiphysics finiteelement methods are often employed [7]. The nonuniformity of the electric field leads to nonuniformity of heating. A uniform electric field does not necessarily imply uniform heating, however. The geometry and absorption characteristics of the load as well as its thermal characteristics and, in the case of composites, the material characteristics of the epoxy resins, the carbon fibers and the weave structure affect the heating as a function of time. For these reasons it may be argued that each electromagnetic (EM) heating problem should be solved with the design of a bespoke applicator or antenna system to develop the desired heating profile. An alternate approach is the use of a standard applicator design and a control system to attempt to optimize the uniformity of heating [8]. Microwave reflectors (mode stirrers) move inside the cavity to randomize the field pattern and are also found in both industrial [9], [10] and domestic ovens.

Several examples of converted domestic microwaves exist in the literature. These have been used in composites applications [11]-[13] as well as other areas such as biological sciences [14] and in the production of ceramics [15], [16] and food preparation [17], [18]. However, there is little or no discussion or comparison of the control algorithms in these examples and there are no examples of Smith predictors used in this application. A great deal of research exists on the use of domestic microwaves for food preparation, for example [19]. The problem of nonuniform heating is experienced in food preparation, for which several tests to determine the heating uniformity have been developed [20]-[23]. Nevertheless, the position of the load and its EM and thermal characteristics greatly influence the results, heavily limiting their applicability to other load materials, geometries and positions of the load in the applicator. Epoxies used in carbon composites are considerably less absorbing than foodstuffs which contain a high fraction of liquid water. The relative lack of absorption in composite loads gives rise to strong standing wave patterns and heating uniformity problems. The relatively good conductivity of carbon fiber results in induced currents and joule heating. This effect is dependent on the fiber fraction and weave structure and is exploited to cure carbon fiber by lowerfrequency methods, for example [24].

Domestic microwave ovens were initially produced using mains frequency, transformer derived, power supplies operated using an ON/OFF control scheme, in which only the rated magnetron output power or no output power was available. Graduation of the average microwave power in the applicator 


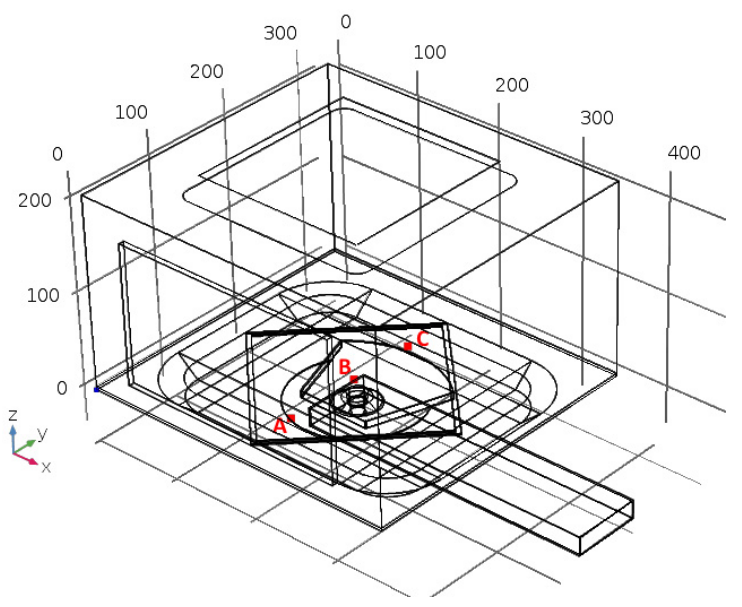

Fig. 1. CAD geometry of the microwave including a composite laminate. Optical thermocouples are placed at points A, B, and C on top of the laminate.

was achieved by varying the ON to OFF time of the magnetron over the course of several thermal time constants of the load (for example, $20 \mathrm{~s}$ ON, $10 \mathrm{~s}$ OFF). Voltage source inverter [25] and current source inverter [26], [27] switchedmode power supplies (SMPSs) have been proposed to reduce weight and cost. These advantages are principally due to the removal of the mains frequency transformer. An SMPS approach has recently become available in mass produced domestic microwaves. It often allows a limited range of continuous control over the average magnetron anode current and therefore average microwave power output. However, a minimum anode current is required to sustain microwave oscillation, above this threshold microwave power output is proportional to anode current. Below the threshold, oscillation does not occur.

\section{Description OF THE MicrowaVe IN THIS WORK}

The microwave used in this work is a Panasonic NN-CF778. It has no turntable and a flat applicator "floor". The manufacture's power electronics consist of a power factor correction circuit and a current source inverter based SMPS. It provides a limited range of power output control (nominally $450 \mathrm{~W}-1 \mathrm{~kW}$ ). The magnetron maximum output power is nominally $1 \mathrm{~kW}$ at $2.45 \mathrm{GHz}$. The internal applicator dimensions are $354 \mathrm{~mm}(W) \times 325 \mathrm{~mm}(D) \times 207 \mathrm{~mm}(H)$. The microwave consists of several parts. The magnetron output enters a waveguide via an E-plane coupler that is modeled as a simple rectangular port in Fig. 1. The waveguide passes under the applicator ending approximately in the center of the applicator. A low power synchronous motor rotates a metallic coupling piece at $5 \mathrm{rpm}$. The motor shaft is sheathed in plastic and the motor body is electrically connected to the waveguide broad wall. The coupling piece, which is mechanically coupled to the motor shaft via the plastic sheath, protrudes through a hole in the waveguide E-plane surface and into the bottom of the applicator. Energy is coupled from the waveguide into the coupling piece as an induced current this then reradiates energy into the applicator. The electric field in the applicator is redistributed as a function of time due to the rotation of the coupling piece. The floor of the applicator is a ceramic

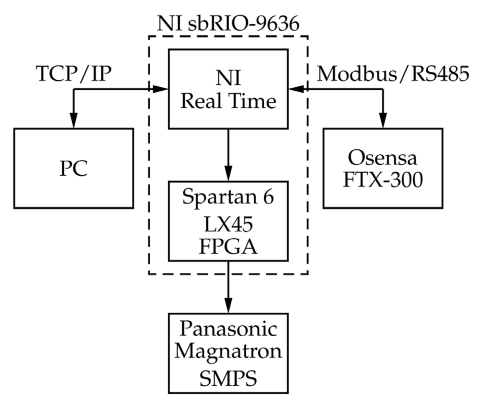

Fig. 2. System architecture.

plate which covers the coupling piece and acts as an RF window. This oven appears to be one possible implementation of European Patent EP 2348257 B1.

\section{A. Hardware Modification}

A system diagram of the modified microwave equipment is shown in Fig. 2. The key modifications are as follows.

1) Isolate the SMPS control signals from the OEM embedded system and replace with signals derived from a custom embedded system, having been suitably level shifted by some trivial circuitry.

2) Short circuit the contactors of a power relay, which disconnects mains power after $8 \mathrm{~min}$ of inactivity on the OEM embedded system user interface.

3) Connect the magnetron cooling fan across the mains power inlet (so that it runs continuously).

4) Fabricate and attach microwave chokes to admit the vacuum lines and fiber optic thermocouples (FOTs). The FOT unit is an Osensa FTX-300, having calibrated accuracy of at least $\pm 0.10{ }^{\circ} \mathrm{C}$, and precision $0.01{ }^{\circ} \mathrm{C}$.

5) The coupling disk motor power supply is connected directly across the ac mains supply and it rotates continuously.

Care has been taken to ensure some key features are not interrupted, including the door interlock mechanism, electronics related to the door interlock, the structure of the door, and the microwave choke.

To find the appropriate drive waveforms to control the OEM power supply, the microwave was run from its front panel using the various cooking power settings while observing the input signals to the SMPS. The SMPS is controlled by a fixedfrequency variable duty cycle pulsewidth modulation (PWM), in which the frequency is $222 \mathrm{~Hz}$ and a duty cycle of $30 \%$ represents approximately $450-\mathrm{W}$ microwave applicator power and $70 \%$ represents approximately $1000 \mathrm{~W}$. "Low" power and "Defrost" mode still require the use of ON/OFF control over long time periods, as the time-averaged power in the applicator is less than the $450-\mathrm{W}$ minimum that the magnetron can produce while sustaining oscillation.

\section{B. Embedded Control System and PC Software}

The embedded system is a National Instruments sbRIO-9636 platform composed of $400-\mathrm{MHz}$ processor running VxWorks with 256-MB RAM and a Xilinx Spartan 6 LX45 field-programmable gate array (FPGA) clocked 


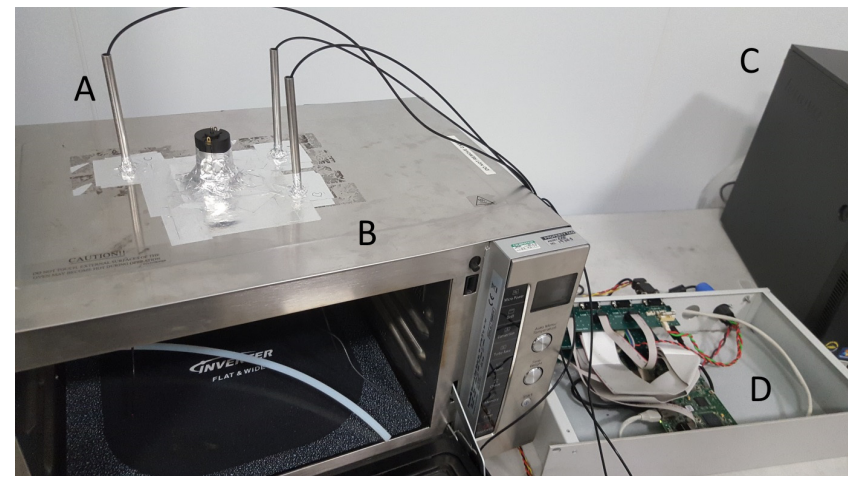

Fig. 3. System photograph. A: Osensa FOTs. Waveguide ports provide mechanical support for the optical fiber and do not support $2.45-\mathrm{GHz}$ propagation. B: Panasonic microwave applicator. C: Desktop PC (for process monitoring by the user). D: Embedded controller including NI sbRIO-9639 (front) and breakout boards (back). The mode stirrer between A and B in the roof of the applicator was added after the work reported here.

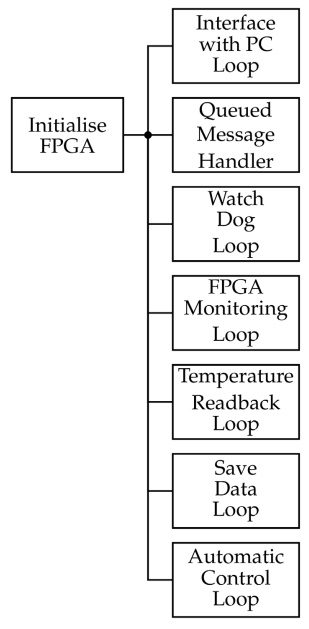

Fig. 4. Real-time system software architecture.

at $40 \mathrm{MHz}$. The PC is a standard workstation; quad core Intel second generation i5 $\times 64,3.3-\mathrm{GHz}$ clock frequency with 4-GB RAM. The PC connects via TCP/IP to the embedded system. All aspects of the system are programmed in LabView or Labview RT.

A labeled photograph of the system is shown in Fig. 3, and the real-time system software architecture is outlined in Fig. 4. In this block diagram, each box represents a loop which, with the exception of the initialization of the FPGA, runs from just after power is applied until power is removed. The automatic control and temperature readback loops have priority over all others and are programmed for a guaranteed execution rate. The FPGA is serviced by the watchdog loop. If the real-time computer crashes, the FPGA reboots the real-time computer automatically and puts the microwave SMPS into a safe state. The FPGA runs a simple finite state machine that generates the required PWM signal. The state machine on the FPGA is monitored by the FPGA monitoring loop in the RT system. The temperature, control parameters and system state are decimated and saved to SD Card as plain text with 1-s resolution. The interface with the PC administers a TCP/IP connection and the queued message handler sends messages to the other loops, based on the data received from the experimenter's PC. Representative data are sent to the PC directly. This data is not saved as it is only required if the experimenter is monitoring the process. The set point profile and control configurations are saved on the real-time computer making it entirely autonomous after the start of a cure cycle.

\section{Control Modes}

The automatic control loop includes several control algorithms. A "Manual" allows the microwave applicator power to be selected by the user. There is no automatic control in this mode. A widely used discretized PID controller with filtering on the differential gain [28] is implemented with a sampling rate of $0.1 \mathrm{~s}$. A PID + Smith predictor is also implemented using the same discretized PID controller as above but coupled to an internal model of the system [29]-[31].

The objective of a Smith predictor is to permit the PID controller to act on the plant without the influence of the system delays. The system model is shown in Fig. 5 and includes the oven power electronics/magnetron delay (a threshold delay), composite thermal mass and heating and cooling time constants, which are different from each other. The model also includes the delay in measuring the temperature due to the latency of the optical thermocouple and the heat transfer into the thermocouple tip. The heating time constant is dominated by surface heating in this work. The high electrical conductivity of the carbon fibers (see Table II) in the laminate reduces the skin depth to approximately $44 \mu \mathrm{m}$. The heating of the composite is restricted to the outer $3 \%$ of its volume. The inner parts are heated by thermal conduction from the outer parts. The heating time constant is still considerably shorter than the cooling time constant, even for a high surface area to volume ratio structure such as a thin laminate. This is ascribed to the thermal insulation provided by the air in the cavity and the breather material. The cooling time constant is dependent on heat transfer from the surface of the composite conduction/convection/radiation into the bagging materials and then into the air in the applicator. The saturation model prevents the power demand exceeding the maximum the oven can deliver and prevents it falling below zero in the case of unexpected or unbounded inputs. The threshold delay model accounts for the time required to build sufficient space charge in the magnetron for oscillation to begin. This delay is only experienced when switching on the magnetron, thereafter the power can be changed or removed almost instantly from a control perspective.

The final control algorithm is a windowed square law controller, which operates as follows: if the measured temperature is more than the window width below the set point, full power is applied. If the measured temperature is above the set point, no power is applied. If the temperature is within the window region, the power applied is proportional to the square of the difference between the set point and measured temperature. The window is defined as a percentage of the set point. This controller has been used with and without an integrator. This controller is included because it has previously been used successfully by Papargyris et al. [32] and is also similar to one 


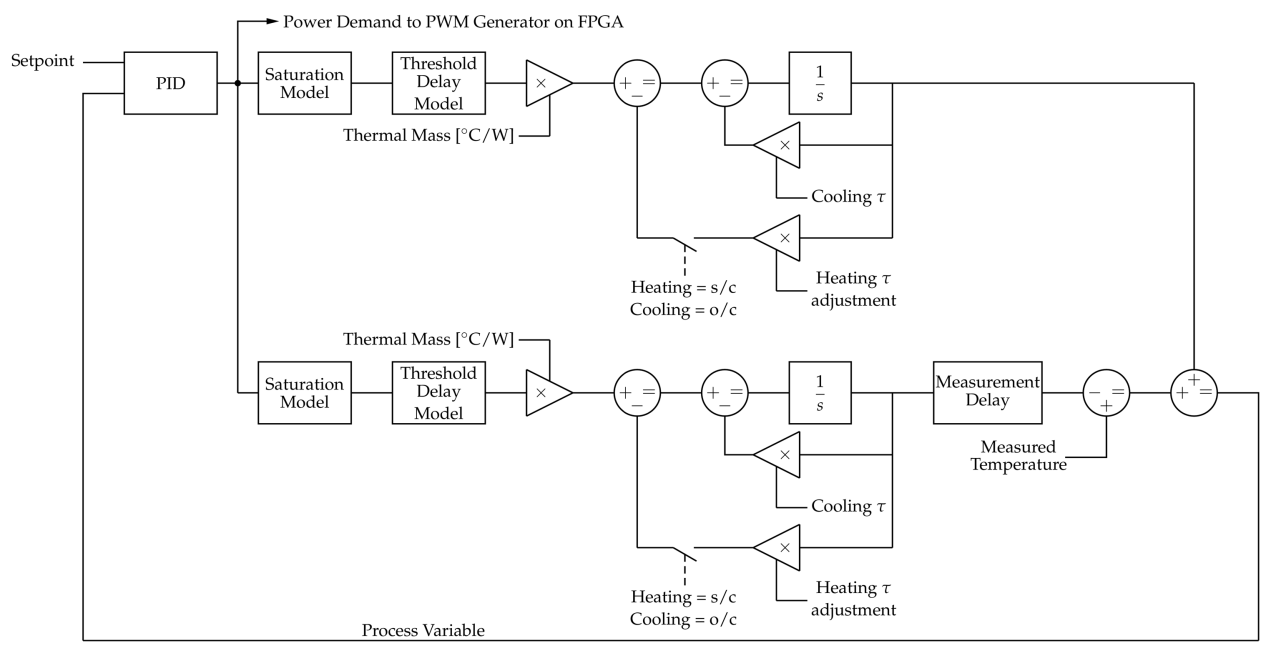

Fig. 5. Smith predictor control structure.

of the control strategies available on the industrial microwaves supplied by Vötsch. ${ }^{2}$

The parameters of the control system models are determined from open loop step response testing. The magnetron space charge build-up delay is $3 \mathrm{~s}$. The delay in measuring a temperature rise on the sample after microwave power is applied to the applicator is $10.6 \mathrm{~s}$. The cooling time constant and the heating modifier are approximately 1100 and $900 \mathrm{~s}$, respectively. The thermal mass parameter of the composite is empirically determined by applying the minimum continuous power $(450 \mathrm{~W})$ and observing the temperature rise, which is linear over modest temperature changes if the losses do not appreciably change. The quotient of the temperature rise and the input power is used as the thermal mass parameter. The thermal mass parameter is verified by running a cure cycle while recording the microwave power applied in the applicator and the composite temperature. The time average of the power coupled with the recorded temperature across the cycle can be used to corroborate the step response test value for the thermal mass parameter. For certain epoxy systems across certain temperature ranges the thermal mass may appear negative as the composite will self-heat due to the exothermic nature of the curing reaction. No attempt to include the chemical reaction in the model has been made so far. In this paper, the thermal mass is assumed constant and is the aggregate value taken over the whole of the cycle. This does not appear to affect the controller appreciably for the temperature ramp rates used in this work.

\section{Available Power Estimation}

To avoid increasing the cost of the system, power is not measured but estimated. A common method for power measurement in heating applications is insertion of a directional coupler and thermistors to measure a known fraction of the forward and reflected power. Including this equipment increases the cost and complexity of the system and requires some careful design, as the waveguide components used in the domestic microwave are not standard shapes. For simplicity,

\footnotetext{
${ }^{2}$ Vötsch Industrietechnik, Balingen, Germany.
}

a water heating method is used to estimate the available power in the cavity assuming all the power is absorbed in the load.

The load is $500 \mathrm{~g}$ water at approximately $20{ }^{\circ} \mathrm{C}$ starting temperature in a cylindrical polypropylene tub without a lid. The water is heated from the starting temperature to approximately $60{ }^{\circ} \mathrm{C}$ at various nominal power levels. Two temperature measurements are taken in the water and one in the cavity air. After heating, the water is immediately stirred with a steel teaspoon in an attempt to homogenise the temperature. The heating data are processed twice. First, a simple calculation is used, which utilizes the start and end time of the heating process, the mass of water, the heat capacity of the water and the average of the two starting temperature measurements subtracted from the two ending temperature measurements. The second method uses a coupled finite element EM and heating simulation. First, a 3-D FE is conducted using full CFD on the water and the air in the cavity as a function of the heating effect. This computationally intensive simulation is used to obtain the Nusselt number for the water and polypropelyene tub. The full CFD of the water and surrounding air takes approximately 90 min on the simulation PC for one input power. This allows a simpler simulation to be used that does not model convective heat loss directly but uses an adjustment to the conductive heat losses to account for convection. Radiation is not modeled as the temperatures are low and radiative heat loss is not a significant effect. The Nusselt number is constant, provided the geometry of the heated parts (the water) do not change. Having obtained the Nusselt number, the computationally simpler simulation is run for a number of microwave power levels to compare with laboratory water heating experiments.

The relationship between the coupled FE simulations and simplified heating calculations are shown in Fig. 6 as a function of the nominal heating power. The disparity is believed to be principally due to the error created by inhomogeneity in the heating requiring an averaging of several temperature measurements, as well as errors judging when heating begins and ends compared to when RF power is first applied and ceases. There is a delay in the reaction of the temperature probes to the input power. The simple timed heating approach 


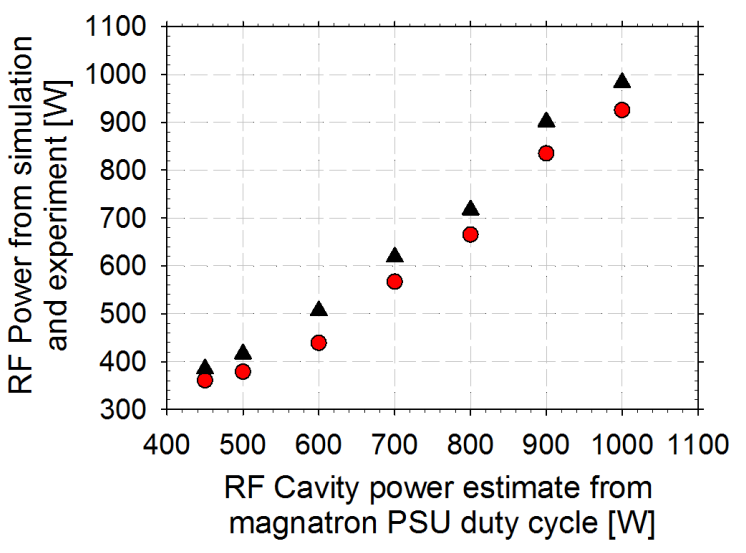

Fig. 6. Water heating experiments to determine available cavity power. Black solid triangles: temperature change as a function of time calculation. Red solid circles: finite element-based power estimate using the adjusted Nusselt number as described in the text.

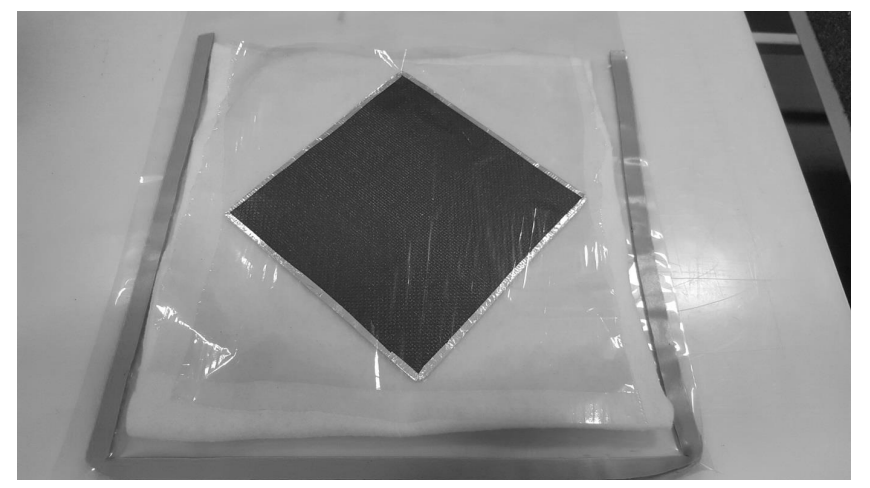

Fig. 7. Partial layup prior to bag sealing. The bag is inserted into the microwave in this orientation (bottom of photograph closest to the door). A top layer of breather material is added and the upper part of the bag is folded down to seal against the "tacky tape." The PTFE vacuum port is inserted prior to sealing the bag by using scalpel to make a small X-shaped hole through which the threads of the port pass sealing against a rubber washer (see Fig. 8).

provides an answer approximately $7 \%$ higher except for the $600-\mathrm{W}$ experiment, which is $13 \%$. Since the controllers used in this paper take the temperature as the process variable, the exact value of power is not of great importance. However, in industrial microwave processes it is common to monitor the cavity power.

\section{Composite Curing Results}

The laminates used in this paper are $200 \mathrm{~mm} \times 200 \mathrm{~mm} \times$ $1.5 \mathrm{~mm}$, consisting of eight-ply of Cycom 5320-1 plain weave prepreg in $[0,90]$ arrangement. This material is produced by Cytec Solvay Group. The cure cycle recommended by the manufacturer is up to $2.8{ }^{\circ} \mathrm{C} / \mathrm{min}$ ramp up to $121{ }^{\circ} \mathrm{C}$, dwell for $3 \mathrm{~h}$ to cure the material, and ramp up to $177{ }^{\circ} \mathrm{C}$ for $2 \mathrm{~h}$ post cure. The ramp has been increased slightly to $3{ }^{\circ} \mathrm{C} / \mathrm{min}$; otherwise the cure cycle meets the manufacturers' specification. The laminates are laid up according to standard out-of-autoclave practices using a vacuum bag and release films in a manner similar to Li et al. [33]. A layup is shown in Figs. 7 and 8. In Fig. 8, the position of the FOTs can be seen entering from the left and these locations are constant for all experiments. One is positioned at the front of the laminate, approximately $2.5 \mathrm{~cm}$ from the edge, one in the middle, and

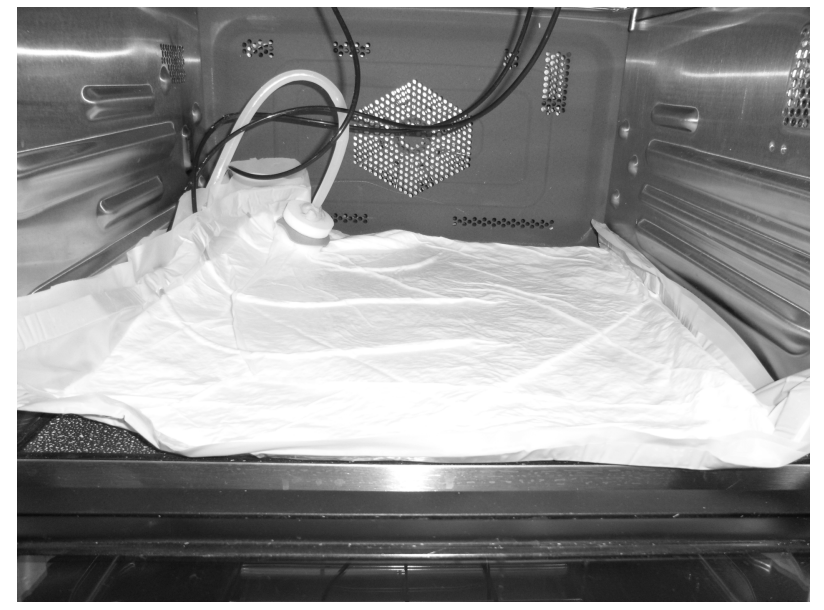

Fig. 8. Bagged composite prior to curing. Three FOTs enter the left side of the bag from the top of the oven; the vacuum port is situated at the back righthand side. The composite is covered with release film, wrapped in breather and bagged. "Tacky tape" seals the bag and vacuum line. The vacuum puck is microwave-transparent PTFE.

one at the back (see Fig. 1). Unlike Li who used "tacky tape" to shield the edges of the carbon fiber, the edges in this work are shielded using a sticky backed aluminum foil (Fig. 7). Great care must be taken to avoid stray fibers entering during the bagging-up process as these interact with the electric field in the applicator immediately after switch-ON, leading briefly to the creation of plasma around the fibers and the loss of vacuum bag integrity.

The main objective of this paper is to assess the control strategies suited to a low cost microwave process. The three control strategies have been used to cure the laminates described above. The process control parameter in each case was the mean of three thermocouple readings. The metric of quality of the control strategy is the absolute error. This is calculated by taking the absolute value of the difference between the set point and the measured temperature for each data point. The absolute error can be used to derive the mean squared error over a particular region of the set point profile for example, ramps and dwells.

The PID control data are shown in Fig. 9, where the black dashed line is the set point, the red solid line is the measured temperature, and the blue dotted line is the absolute error calculated using

$$
E(i)=|\operatorname{SP}(i)-\operatorname{MT}(i)| .
$$

$\mathrm{SP}(\mathrm{i})$ is the set-point value at the $i$ th sample and MT(i) is the measured temperature at the $i$ th sample. The sample rate of the controller is $0.1 \mathrm{~s}$. The relative merit of each control strategy is evaluated in Table I, which compares the mean absolute error of ramp functions and dwells for each control strategy.

The Smith predictor control strategy experimental data are shown in Fig. 10. The PID controller in this strategy has the same gain settings as the standard PID case. The PID parameters were chosen by experimental step response testing of a sacrificial laminate of the same dimensions and material as the experiments shown herein, and by use of a simulator written to mimic the control strategy while also allowing 
TABLE I

Mean Absolute Error for Each Control Strategy for Each Section of the Cure Cycle

\begin{tabular}{cccccc}
\hline \hline Control Strategy & Ramp1 $\left({ }^{\circ} \mathrm{C}\right)$ & Dwell $1\left({ }^{\circ} \mathrm{C}\right)$ & Ramp $2\left({ }^{\circ} \mathrm{C}\right)$ & Dwell $2\left({ }^{\circ} \mathrm{C}\right)$ & Ramp $3\left({ }^{\circ} \mathrm{C}\right)$ \\
\hline PID & 7.750 & 1.547 & 3.131 & 1.176 & 2.655 \\
\hline Smith Predictor & 6.928 & 0.341 & 2.858 & 0.369 & 1.950 \\
\hline PSC & 5.248 & 5.506 & 7.337 & 6.668 & 5.059 \\
\hline
\end{tabular}

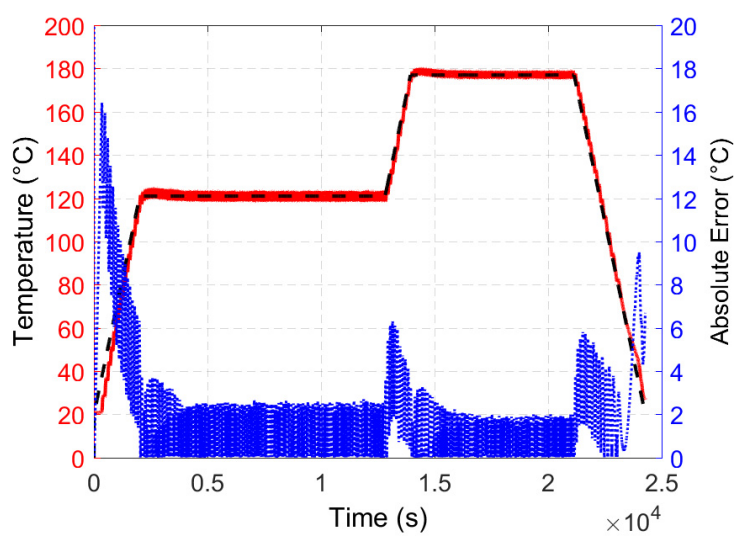

Fig. 9. PID control data of the cure cycle on the laminate described in the text. Black dashed line: set-point profile, red solid line: measured temperature, and blue dotted line: absolute error calculated by the method given in the text.
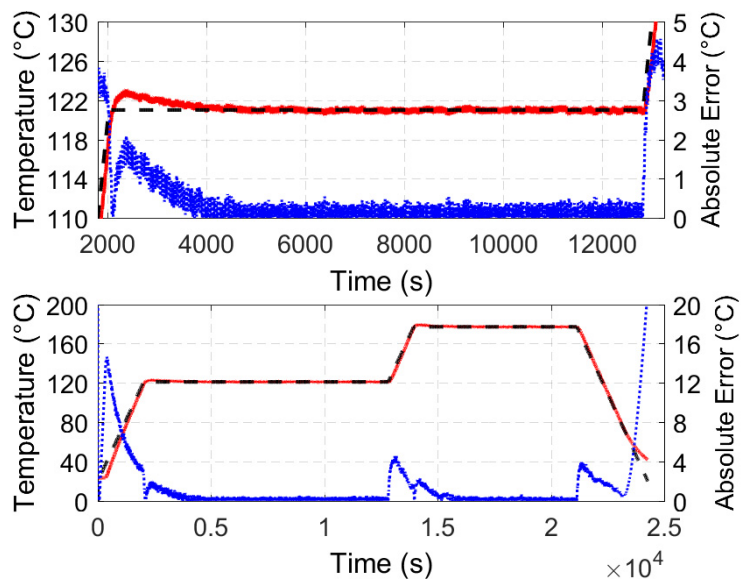

Fig. 10. Smith predictor control data of the cure cycle on the laminate described in the text. Black dashed line: set-point profile, red solid line: measured temperature, and blue dotted line: absolute error calculated by the method given in the text. The upper plot shows an inset of the cure portion of the cycle.

robustness simulation by implementing delay differences and time constant differences between the simulated plant and the internal model of the plant in the controller. The effects of Gaussian additive noise on the temperature measurement and the effects of temperature measurement error are also included in the simulation.

The windowed proportional square controller (PSC) results are shown in Fig. 11. The PSC strategy performs poorly in this application. This method of control is included for comparison and, lacking an integrator, results in steady-state error. The window is chosen as $15 \%$ of the set point and the coefficient of the square law in the window region is 0.57 . These parameters were selected empirically using a simulator similar in design

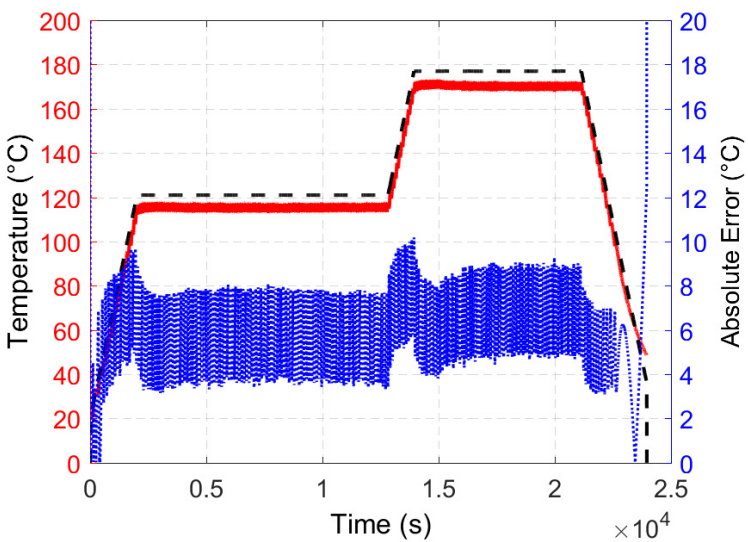

Fig. 11. PSC control data of the cure cycle on the laminate described in the text. Black dashed line: set-point profile, red solid line: measured temperature, and blue dotted line: absolute error calculated by the method given in the text.

to the Smith predictor simulator. The parameters selected keep the process temperature within $15 \%$ of the set point, i.e., within the window after an initial period of full power at the beginning of the cycle. The performance of this controller is limited in this application principally due to the nonlinearity of the plant and the lack of an integrator in the control loop. This algorithm is better suited to a linear microwave curing setup, where microwave power is continuously variable from zero [34]. The manufacturer's specification for temperature control is $\pm 6{ }^{\circ} \mathrm{C}$ (Cytec Cycom 5320-1 Datasheet), which this algorithm falls slightly outside of. To reduce the steadystate error a larger gain coefficient in the window region could be selected, however, increasing this parameter without limit makes an approximation to a hysteresis controller exchanging the steady-state error problem for a temperature ripple problem.

\section{A. Spatial Temperature Variation}

A key outstanding problem in microwave processing is the uniformity of heating. While the use of a domestic microwave is inexpensive and relatively simple to convert, there is limited scope to experiment with uniformity problems. The converted domestic microwave is a multiple-input singleoutput (MISO) system. Other than mode stirrers and rotating coupling pieces or strategically placed absorbing materials, little can be done to affect a change in the standing wave pattern while a cure cycle is running. In this paper, the control parameter is the mean of three temperature measurements equally spaced across one diagonal of the $200-\mathrm{mm}$ laminate. An example of the individual temperature readings for the Smith strategy is shown in Fig. 12. A wide temperature 


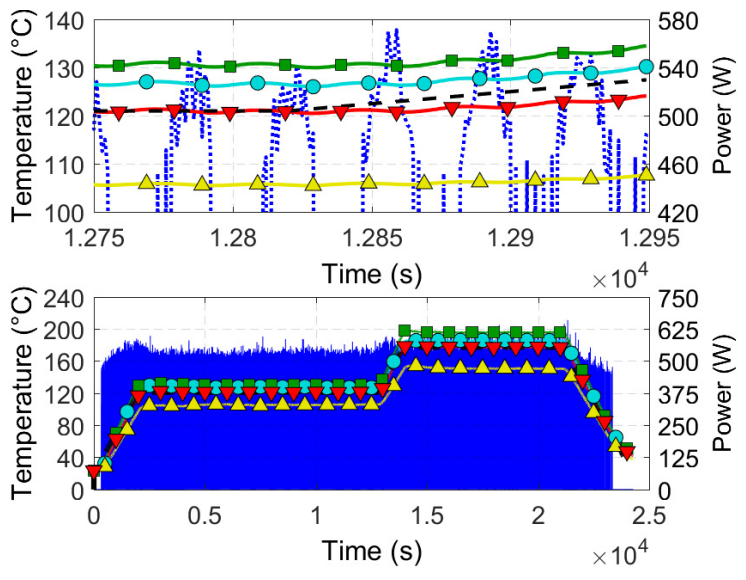

Fig. 12. Individual temperature measurements for the same experiment shown in Fig. 10. Black dashed line: set point, red solid line with red down triangle: mean temperature, cyan solid line with cyan circles: thermocouple A, green solid line with green square: thermocouple B, and yellow solid line with yellow up triangle: thermocouple C. Blue dotted line: applicator microwave power demand. The upper plot is an inset of the beginning of the postcure ramp showing more clearly the power demand and temperature ripple.

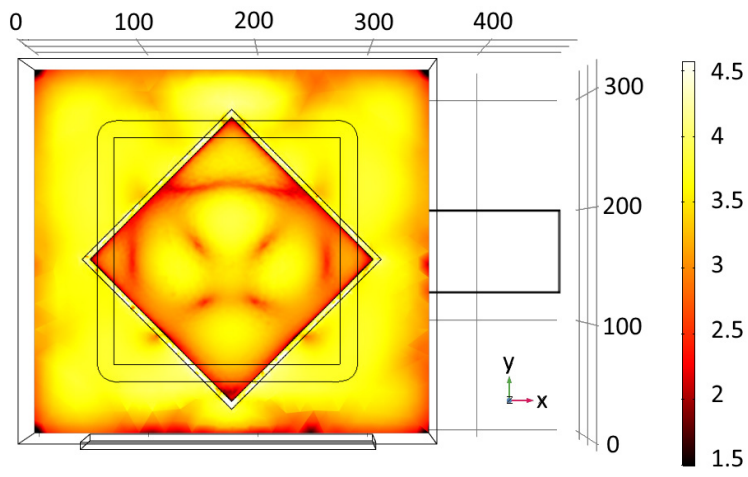

Fig. 13. Common logarithm of the magnitude of electric field, in $\mathrm{V} / \mathrm{cm}$, normal to a plane passing through the center of the composite, viewed from above. Exterior dimensions are in millimeter. The coupling component is in the same position as in Fig. 1.

variation exists far exceeding the prepreg manufacturers' specified $\pm 6{ }^{\circ} \mathrm{C}$.

\section{B. Multiphysics Modeling}

Multiphysics modeling is performed using COMSOL. The FE simulation of electric field is shown in Fig. 13 for the plane passing through the center of the composite. The EM loss density in the composite is shown in Fig. 14. Material parameters are provided in Table II. The permittivity and loss tangent are approximated from [35]. The thermal properties of the composite have been measured using a Hot Disk TPS $2500 \mathrm{~S}$, using standard techniques. The electrical resistivity is approximated from resistance measurements of a $25 \mathrm{~mm} \times 200 \mathrm{~mm} \times 1.5 \mathrm{~mm}$ fully cured sample using aluminum tape tabs which are cured onto the laminate as contacts, although more rigorous methods are available. For example, Zantout and Zhupanska [36] report success with the following procedure while connecting carbon composites to copper bus bars.

1) The composite edges are sanded smooth in a progression of differing sand paper grits, 220, 400, 600 .

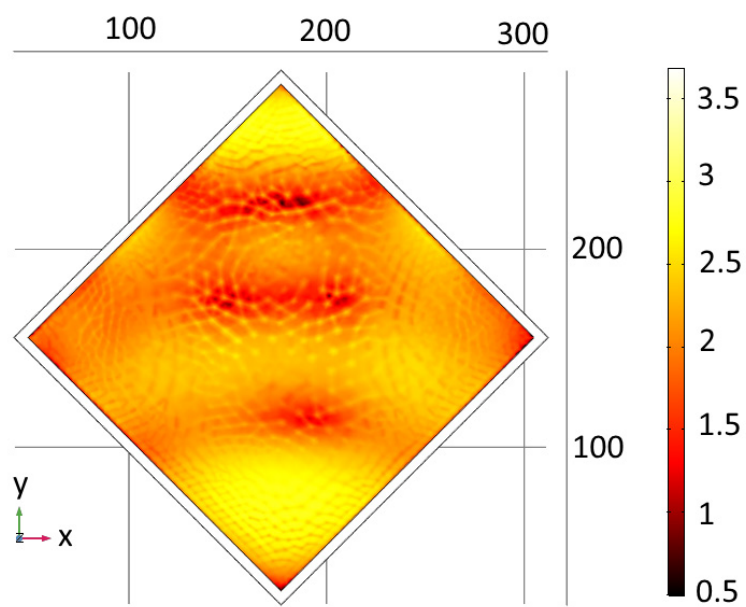

Fig. 14. Common logarithm of EM loss density, in $\mathrm{V} / \mathrm{cm}^{3}$, caused by displacement and induced currents in the laminate due to the RF field in Fig. 13. External dimensions are in millimeter. The coupling component is in the same position as in Fig. 1.

2) The sample is wiped clean with acetone.

3) The sanded ends are coated with an electrically conductive epoxy.

4) The expoy, having cured, is sanded smooth with 600-grit sand paper.

5) A silver paste is applied in between the copper bus bar and the composite.

Böhrk et al. [37] report a simpler setup using stainless steel clamps. They used a four-wire sense connection. In this paper, it is assumed that the parameters are independent of the depth of cure and temperature. The microwave model is as described in Section III. The complex permittivity of the ceramic plate was measured, unsuccessfully, using a common free-space insertion loss technique composed of a time domain-gated vector network analyzer and two wideband horns which face each other with the sample interposed between them. Unfortunately the physical dimensions of the plate are insufficient to prevent significant edge diffraction effects from corrupting the result at the wavelength of interest. The available setup is designed for frequencies greater than $5 \mathrm{GHz}$. Ideally a similar setup using a waveguide to contain the sample and prevent edge effects would be used. The insertion loss is approximately $1 \mathrm{~dB}$. It is assumed that the ceramic is alumina $\left(\mathrm{Al}_{2} \mathrm{O}_{3}\right)$ due to its low cost given the mass production nature of the microwave, but this has not been confirmed. The complex permittivity is taken from [38].

The heating effect is found by first computing the electromagnetic loss density in the composite for ten positions of the coupling disk equally spaced, $36^{\circ}$ apart, around a circle. This information is then used in a second simulation, which calculates the heating effect of this EM loss on the composite as a function of time. Heat transfer away from the composite, by convection from the top surface, is modeled using a free air horizontal plate approximation, but conduction into the ceramic plate is not modeled neither is radiation.

The curing consumables (bag, breather etc.) are also not modeled. Since the control system attempts to control the temperature this too should be implemented in the simulation. This is possible by coupling a MATLAB simulation of the 
TABLE II

Material Electrical and Thermal Parameters for Multiphysics Modeling. $X, Y$, And $Z$ Are as Defined in Fig. 1

\begin{tabular}{ccccc}
\hline \hline Parameter & Composite & Aluminium Tape & Alumina & Unit \\
\hline Permittivity & $4.5-\mathrm{j} \cdot 0.5$ & - & $8.9-\mathrm{j} \cdot 0.009$ & - \\
\hline Electrical Conductivity & $\begin{array}{c}\mathrm{x}=541.86 \\
\mathrm{y}=541.86 \\
\mathrm{z}=0\end{array}$ & $3.774 \times 10^{7}$ & 0 & $\mathrm{~S} \cdot \mathrm{m}^{-1}$ \\
\hline Heat Capacity & 850 & 900 & 900 & $\mathrm{~J} \cdot \mathrm{kg}^{-1} \cdot \mathrm{K}^{-1}$ \\
\hline Thermal Conductivity & $\begin{array}{l}\mathrm{x}=1541.2 \\
\mathrm{y}=1541.2 \\
\mathrm{z}=652.03\end{array}$ & 238 & 27 & $\mathrm{~W} \cdot \mathrm{m}^{-1} \cdot \mathrm{K}^{-1}$ \\
\hline Gravimetric Density & 1126 & 2700 & 3900 & $\mathrm{~kg} \cdot \mathrm{m}^{-3}$ \\
\hline
\end{tabular}

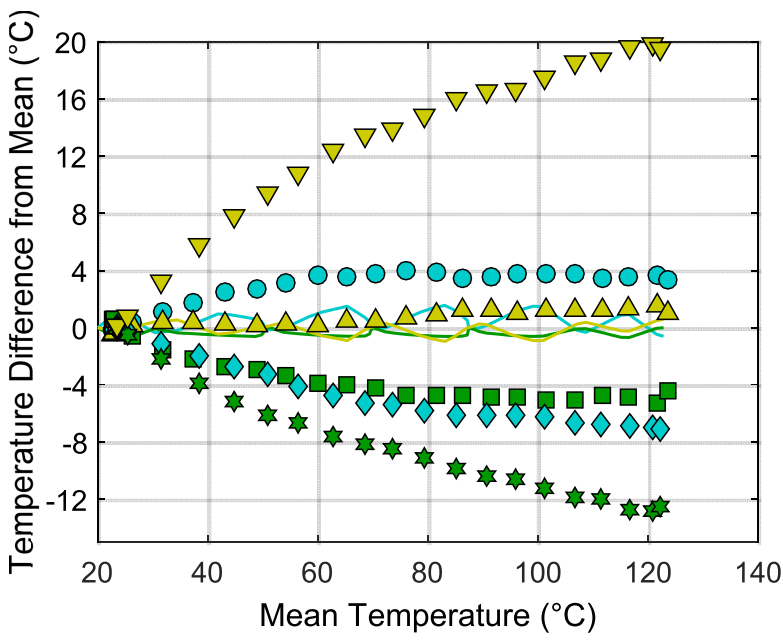

Fig. 15. Temperature difference between the mean temperature for each data set and each thermocouple or FE "probe" for three data sets over the period of the first ramp. Smith predictor with vacuum (from Fig. 12) temperature probe A: yellow down triangle, B: green hexagram, C: cyan diamond. Smith predictor without vacuum temperature probe A: yellow up triangle, B: green square, C: cyan circle. Solid lines: coupled FE simulation temperature probe A: yellow, B: green, C: cyan.

controller to COMSOL, but it has not been attempted in this work because the principal aim of this simulation is to estimate the likely heating uniformity for which a constant, $160 \mathrm{~W}$, $\mathrm{RF}$ power is sufficient.

The simulated relative temperature distribution is substantially more uniform than has been found experimentally. This effect was investigated by running part of a cure cycle under the same conditions as in the prior results, without any vacuum using the Smith predictor controller. Three sets of data over the period of the initial ramp from room temperature to $121^{\circ} \mathrm{C}$ are shown in Fig. 15. The deviation of the three thermocouples from the mean temperature in each data set is compared. The data sets are the coupled FE simulation, the no vacuum Smith predictor controlled data and the with vacuum Smith predictor data.

The "with-vacuum" Smith predictor data are also displayed as a function of time in Fig. 12. The effect of the coupling disk rotation can be inferred from the periodicity of the simulation (solid line) data in Fig. 15. The spread of the "no-vacuum" measured temperature in Fig. 15 is much more desirable than the "with-vacuum" data, but comparing the simulation with
TABLE III

SUMMARY OF DSC DATA

\begin{tabular}{ccc}
\hline \hline Control Strategy & Enthalpy $(\mathrm{J} / \mathrm{g})$ & Depth of Cure $(\%)$ \\
\hline PID & 23.49 & 84.5 \\
\hline PID - 2 & 0.7552 & 99.5 \\
\hline PID - 3 & 27.77 & 81.8 \\
\hline Smith Predictor & 4.874 & 96.8 \\
\hline PSC & 3.842 & 97.5 \\
\hline
\end{tabular}

the "no-vacuum" data there is still a considerable disparity; however, the simplifications made during the simulation are very likely to account for these differences.

We conclude that the majority of the spatial nonuniformity in the measurements presented here is due to airflow over the composite. Stray fibers cause plasma discharge early in the cure cycle and the vacuum integrity is lost. Air from the cavity is sucked into the vacuum bag throughout the rest of the cure cycle.

It is not possible to predict the size of the holes or the resulting airflow or convective heat loss, however, bagging with copious amounts of breather material and fastidious preparation has resulted in good vacuum integrity throughout some other cure cycles not reported here. We have also attempted bagging with Kapton which appears to be more robust.

\section{Composite Thermal AnAlysis}

Differential scanning calorimetry (DSC) and dynamic mechanical analysis (DMA) has been conducted on three samples, correlated with the position of the thermocouples on three laminates cured using each of the three control systems. DSC is a thermoanalytical technique used to interpret thermal transitions in materials such as polymers. A TA Instruments Q20 was used to conduct a dynamic temperature scan (heat flux as a function of temperature) to measure any residual exothermic heat left within a cured panel. Fig. 16 shows the DSC results where exothermic is up. The uncured sample enthalpy was found to be $152.36 \mathrm{~J} / \mathrm{g}$. The residual heat and depth of cure are shown in Table III. The DSC data for the PID laminate showed considerable position dependent variation so several values are presented. The composite manufacturer's datasheet states $93 \%$ or better depth of cure should be taken as fully cured. 


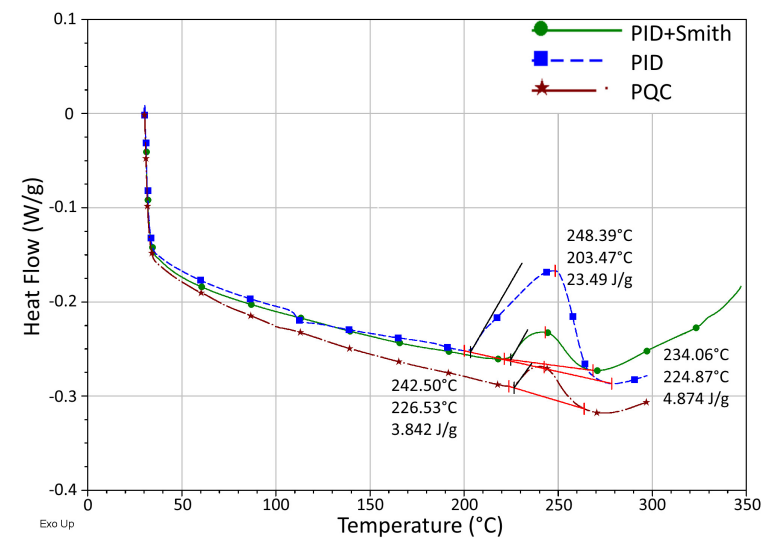

Fig. 16. DSC data for one position on each laminate overlaid with analysis markers to provide the enthalpy. An uncured sample was measured at $152.36 \mathrm{~J} / \mathrm{g}$. Blue dashed line with squares: PID, green solid line with circles: Smith predictor, brown dotted-dashed line with stars: PSC.

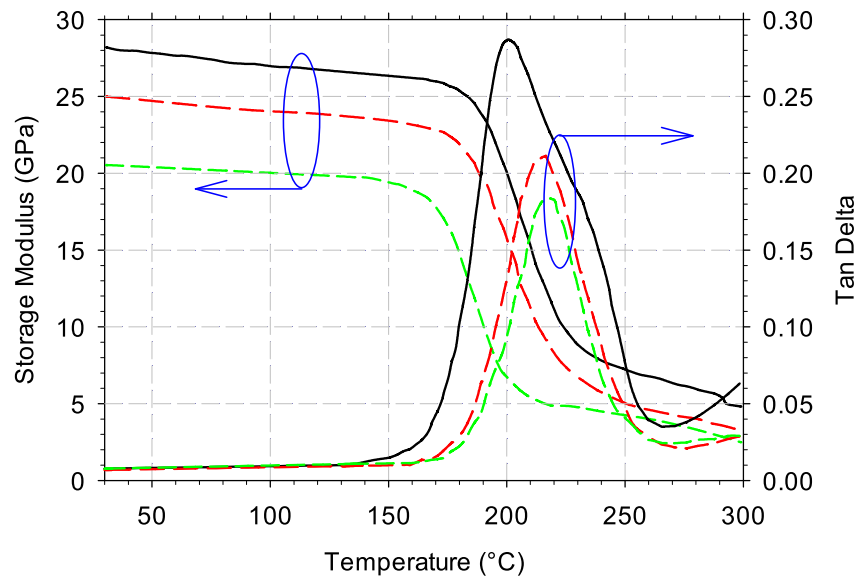

Fig. 17. Exemplar DMA data for black solid lines: Smith predictor, red long dashed lines: PSC, green medium dashed lines: PID.

Another important property for composite materials is the glass transition temperature $\left(T_{g}\right)$, measured using a PerkinElmer DMA800. The $T_{g}$ is a measure of the temperature where there is a reversible reduction in molecular mobility, upon cooling, signifying the polymer is transitioning from a "glassy" to a "rubbery" state (crosslinked). Three tests were conducted per area and the results were averaged. Areas $\mathrm{A}, \mathrm{B}$, and $\mathrm{C}$ are shown in Fig. 1 and correspond to the thermocouple positions. The data are summarized in Table IV and exemplar data are shown in Fig. 17. From these data, area $\mathrm{B}$ consistently exhibits a higher $T_{g}$ value than areas $\mathrm{A}$ and $\mathrm{C}$. This is due to the material experiencing greater heat in the center region of the composite panel. This is in agreement with Fig. 13, where the higher simulated E-field in the center should result in a larger induced fiber current and therefore ohmic heating. Laminates positioned in areas $\mathrm{A}$ and $\mathrm{C}$ have larger temperature gradients, demonstrating that the heat distribution within these laminates is not uniform.

\section{Use of Domestic Microwave Ovens FOR COMPOSITES RESEARCH}

This section summarizes the problems and benefits of domestic microwave use in composites research. The spatial
TABLE IV

DMA Data Showing Glass Transition Temperature From THE AREa ARound Each THERMocouple on ONE Laminate CURED USING EACH CONTROL STRATEgY

\begin{tabular}{lccc}
\hline \hline Control & $\mathrm{T}_{\mathrm{g}}$ 'A' $\left({ }^{\circ} \mathrm{C}\right)$ & $\mathrm{T}_{\mathrm{g}}$ ' $\mathrm{B}^{\prime}\left({ }^{\circ} \mathrm{C}\right)$ & $\mathrm{T}_{\mathrm{g}}$ 'C' $\left({ }^{\circ} \mathrm{C}\right)$ \\
\hline PID & 232 & 234 & $198\left(2^{\text {nd }} \mathrm{pk}\right)$ \\
\hline Smith predictor & $207\left(2^{\text {nd }} \mathrm{pk}\right)$ & 225 & 225 \\
\hline PSC & 214 & NA & 212 \\
\hline
\end{tabular}

variation of temperature is undesirable for curing laminates. However, many studies are suited to a converted domestic oven, in particular, those that use samples somewhat smaller than a wavelength, for example, rheology, resin formulation, studies involving the dispersion of particles in resins and studies where there is thought to be a real risk of fire.

\section{A. Problems}

1) The cavity is lightly loaded. Strong standing wave patterns are problematic in terms of heading uniformity. A larger load is desirable, however, the volume of the area of the oven floor is limited somewhat especially when the space consumed by vacuum bag and consumables is taken into account.

2) Stray fibers on the edge of laminate and on the bag/breather material causes breakdown of air and bag perforation, loss of vacuum and, therefore, loss of consolidation. In this paper, aluminum tape has been used on the edge of the laminates. While this appears to provide acceptable results, it does little to ameliorate the problem of stray fibers, which easily puncture the bag through being the source of a discharge. In our more recent work, not reported here, Kapton bagging material has proved more resilient to the effects of arcing due to stray fibers. The arcing is due to individual stray fibers, which are difficult to detect with the naked eye. The arcing around individual stray fibers is not related to any measurement or control aspects. The arcing occurs as soon as the RF energy enters the cavity for the first time and the bag is burst almost instantly by the high temperature the fiber reaches. Control system optimization cannot ameliorate this effect. It is something workers must be aware of when microwaving carbon composites. An antistatic compressed air system has been used to remove many but often not all of the strays. Only one stray is required to burst the bag. Despite clean room conditions a myriad of work is conducted in our laboratory including weaving and the dispersion of particles and fillers. There are a lot of stray fibers in the environment. In these circumstances it is very difficult to remove all the stray fibers.

3) The minimum energy required for oscillation of the magnetron causes some unavoidable ripple in temperature at any given position. We have shown that this can be ameliorated to some extent by proper implementation of existing control techniques allowing the control parameter to stay within the manufacturer's recommended range. 
4) The key problem from a control perspective is that there is only one microwave source. There is no opportunity to implement any multiple-input multiple-output (MIMO) control techniques. This is the main limitation of the domestic microwave.

\section{B. Benefits}

1) The domestic microwave is relatively inexpensive compared to a bespoke solution, and contains both the microwave oscillator and power supply.

2) It can be easily replaced should it break down.

3) Conversion is relatively simple.

4) By implementing a custom embedded system the control strategy can be as complex as desired within the stated MISO limits.

5) Ports for vacuum and thermocouples are easily added.

Mechanical features including a door, with a window and interlocks, a light, convection oven (if considering a dual mode heating system), a mode stirrer assuming the model of oven has one and a steam sensor among other items are available and generally only require some relatively trivial electronics to interface with a microcontroller or embedded computer.

\section{CONCLUSION}

This paper has outlined the conversion of a low-cost domestic microwave oven for use in composite curing applications. For the first time, we have applied a PID + Smith predictor MISO predictive control strategy to the microwave heating of carbon fiber. We have compared this with two controllers lacking a predictive element. Experimental data have been provided for each control strategy based on a $200 \mathrm{~mm} \times$ $200 \mathrm{~mm}$ eight-ply prepreg laminate and the degree of cure established for the test samples by thermal analysis techniques. Multiphysics simulation was used to model the EM and heating effects in the system, and a common and inexpensive method of approximating the available microwave power was used. The low cost of the microwave components and the ease of conversion are desirable characteristics in this application; nevertheless, the ultimate utility of converted microwaves is limited by their single microwave source, which limits the possibility of effectively controlling the energy distribution in the cavity to promote uniform heating. Our future work will focus on MIMO systems based on phased array, timeswitched, or variable-frequency techniques to ameliorate the temperature inhomogeneity as far as possible.

\section{REFERENCES}

[1] M. A. Stuchly and S. S. Stuchly, "Industrial, scientific, medical and domestic applications of microwaves," Proc. Inst. Elect. Eng.-Phys. Sci., Meas. Instrum., Manage. Edu.-Rev., vol. 130, no. 8, pt. A, pp. 467-503, Nov. 1983.

[2] Lifting Off: Implementing the Strategic Vision for UK Aerospace, Dept. Business Innovation and Skills, HM Goverment U.K., 2013.

[3] I. Zainol, R. Day, and F. Heatley, "Comparison between the thermal and microwave curing of bismaleimide resin," J. Appl. Polymer Sci., vol. 90, no. 10, pp. 2764-2774, 2003.

[4] F. Y. C. Boey and S. W. Lye, "Void reduction in autoclave processing of thermoset composites," Composites, vol. 23, no. 4, pp. 266-270, 1992.

[5] L. Feher, K. Drechsler, J. Filsinger, and R. Wiesehofer, "Microwave processing of advanced composites with high electromagnetic power heating," Sampe J., vol. 43, no. 2, pp. 77-82, Mar./Apr. 2007.
[6] Y. Qiu and M. Hawley, "Uniform processing of V-shaped and Tri-planar composite parts using microwaves," J. Composite Mater., vol. 35, no. 12 pp. 1062-1078, 2001

[7] S. R. S. Dev, Y. Gariépy, V. Orsat, and G. S. V. Raghavan, "Finite element modeling for optimization of microwave heating of in-shell eggs and experimental validation," Int. J. Numer. Modell. Electron. Netw., Devices Fields, vol. 25, no. 3, pp. 275-287, 2012.

[8] Y. Sun, T. Kuehner, G. Link, T. Kayser, and J. Jelonnek, "A novel temperature control approach of distributed microwave feeding systems," in Proceedings of the International Scientific Colloquium 'Modeling for Electromagnetic Processing', E. Baake, Ed. Hanover, Germany: Leibnitz Univ., 2014, pp. 155-161.

[9] P. Plaza-Gonzalez, J. Monzo-Cabrera, J. M. Catala-Civera, and D. Sanchez-Hernandez, "New approach for the prediction of the electric field distribution in multimode microwave-heating applicators with mode stirrers," IEEE Trans. Magn., vol. 40, no. 3, pp. 1672-1678, May 2004.

[10] P. Plaza-Gonzalez, J. Monzo-Cabrera, J. M. Catala-Civera, and D. Sanchez-Hernandez, "Effect of mode-stirrer configurations on dielectric heating performance in multimode microwave applicators," IEEE Trans. Microw. Theory Techn., vol. 53, no. 5, pp. 1699-1706, May 2005.

[11] C. Nightingale and R. J. Day, "Flexural and interlaminar shear strength properties of carbon fibre/epoxy composites cured thermally and with microwave radiation," Composites A, Appl. Sci. Manuf., vol. 33, no. 7, pp. 1021-1030, 2002.

[12] S. Rao and R. Rao, "Cure studies on bifunctional epoxy matrices using a domestic microwave oven," Polymer Test., vol. 27, no. 5, pp. 645-652, 2008.

[13] M. Wallace, D. Attwood, R. J. Day, and F. Heatley, "Investigation of the microwave curing of the PR500 epoxy resin system," J. Mater. Sci. vol. 41, no. 18, pp. 5862-5869, 2006.

[14] M. Pagnotta, A. Nolan, and L. Kim, "A simple modification of a domestic microwave oven for improved temperature control," J. Chem. Edu., vol. 69, no. 7, p. 599, 1992.

[15] D. Keyson et al., "Domestic microwave oven adapted for fast heat treatment of $\mathrm{Ba}_{0.5} \mathrm{Sr}_{0.5}\left(\mathrm{Ti}_{0.8} \mathrm{Sn}_{0.2}\right) \mathrm{O}_{3}$ powders," J. Mater. Process. Technol., vol. 189, nos. 1-3, pp. 316-319, 2007.

[16] S. Zouai et al., "A new and economic approach to synthesize and fabricate bioactive diopside ceramics using a modified domestic microwave oven. Part 2: Effect of $\mathrm{P}_{2} \mathrm{O}_{5}$ additions on diopside bioactivity and mechanical properties," Mater. Sci. Eng., C, vol. 61, pp. 553-563, Apr. 2016.

[17] Z. Okmen and A. Bayindirli, "Modification of a household microwave oven for continuous temperature and weight measurements during drying of foods," J. Microw. Power Electromagn. Energy, vol. 35, no. 4, pp. 225-231, 2000.

[18] K. Pitchai, J. Chen, S. Birla, D. Jones, and J. Subbiah, "Modeling microwave heating of frozen mashed potato in a domestic oven incorporating electromagnetic frequency spectrum," J. Food Eng., vol. 173, pp. 124-131, Mar. 2016.

[19] G. Sumnu and S. Sahin, "16-Recent developments in microwave heating," in Emerging Technologies for Food Processing, D. Sun, Ed. San Diego, CA, USA: Academic, 2005, pp. 419-444.

[20] M. J. Swain, A. Spinassou, and M. V. L. Swain, "A test procedure to characterise the heating performance of domestic microwave ovens," Int. J. Food Sci. Technol., vol. 43, no. 1, pp. 15-23, 2008.

[21] C. James, M. V. Swain, S. J. James, and M. J. Swain, "Development of methodology for assessing the heating performance of domestic microwave ovens," Int. J. Food Sci. Technol., vol. 37, no. 8, pp. 879-892, 2002.

[22] K. Pitchai, S. L. Birla, D. Jones, and J. Subbiah, "Assessment of heating rate and non-uniform heating in domestic microwave ovens," J. Microw. Power Electromagn. Energy, vol. 46, no. 4, pp. 229-240, 2012.

[23] V. Rakesh, A. K. Datta, M. H. G. Amin, and L. D. Hall, "Heating uniformity and rates in a domestic microwave combination oven," J. Food Process Eng., vol. 32, no. 3, pp. 398-424, 2009.

[24] S. A. Hayes, A. D. Lafferty, G. Altinkurt, P. R. Wilson, M. Collinson, and P. Duchene, "Direct electrical cure of carbon fiber composites," Adv. Manuf. Polymer Composites Sci., vol. 1, no. 2, pp. 112-119, 2015.

[25] M. Ishitobi, S. Moisseev, L. Gamage, M. Nakaoka, D. Bessyo, and H. Omori, "Pulse width and pulse frequency modulation pattern controlled ZVS inverter type AC-DC power converter with lowered utility AC grid side harmonic current components for magnetron drive," in Proc. IEEE 33rd Annu. Power Electron. Specialists Conf., Jun. 2002, pp. 2062-2067.

[26] B. M. Hasanien and K. F. A. Sayed, "Current source ZCS PFM DC-DC converter for magnetron power supply," in Proc. 12th Int. Middle-East Power Syst. Conf., 2008, pp. 464-469. 
[27] Y.-R. Yang, "A magnetron power supply with transition-mode ZVS inverter," in Proc. IEEE 10th Int. Conf. Power Electron. Drive Syst.,

[28] K. J. Astrom and T. Hagglund, PID Controllers: Theory, Design and Tuning, 2nd ed. Triangle Park, NC, USA: Instrum. Soc. Amer., 1995.

[29] K. J. Astrom, C. C. Hang, and B. C. Lim, "A new Smith predictor for controlling a process with an integrator and long dead-time," IEEE Trans. Autom. Control, vol. 39, no. 2, pp. 343-345, Feb. 1994.

[30] M. R. Matausek and A. D. Micic, "A modified Smith predictor for controlling a process with an integrator and long dead-time," IEEE Trans. Autom. Control, vol. 41, no. 8, pp. 1199-1203, Aug. 1996.

[31] Z. J. Palmor, "Time-delay compensation: Smith predictor and its modifications," in Control System Fundamentals, W. S. Levine, Ed. Boca Raton, FL, USA: CRC Press, 2011, pp. 9-124-9-146.

[32] D. A. Papargyris, R. J. Day, A. Nesbitt, and D. Bakavos, "Comparison of the mechanical and physical properties of a carbon fibre epoxy composite manufactured by resin transfer moulding using conventional and microwave heating," Composites Sci. Technol., vol. 68, nos. 7-8, pp. 1854-1861, 2008.

[33] N. Li, Y. Li, X. Hang, and J. Gao, "Analysis and optimization of temperature distribution in carbon fiber reinforced composite materials during microwave curing process," J. Mater. Process. Technol., vol. 214, no. 3, pp. 544-550, 2014.

[34] A. Nesbitt et al., "Development of a microwave calorimeter for simultaneous thermal analysis, infrared spectroscopy and dielectric measurements," Meas. Sci. Technol., vol. 15, no. 11, p. 2313, 2004.

[35] L. Zong, S. Zhou, N. Sgriccia, M. C. Hawley, R. Sun, and L. C. Kempel, "Dielectric properties of an epoxy-amine system at a high microwave frequency," Polymer Eng. Sci., vol. 45, no. 12, pp. 1576-1580, 2005.

[36] A. E. Zantout and O. I. Zhupanska, "On the electrical resistance of carbon fiber polymer matrix composites," Composites A, Appl. Sci. Manuf., vol. 41, no. 11, pp. 1719-1727, 2010.

[37] H. Böhrk, P. Leschinski, and T. Reimer, "Electrical resistivity measurement of carbon-fiber-reinforced ceramic matrix composite under thermomechanical load," Composites Sci. Technol., vol. 76, pp. 1-7, Mar. 2013.

[38] A. C. Metaxas and R. J. Meredith, "Engineers' handbook of industrial microwave heating (Energy Engineering)," in Institute of Engineering Technology, vol. 25. Stevenage, Hertfordshire, U.K.: IEE, 2007.

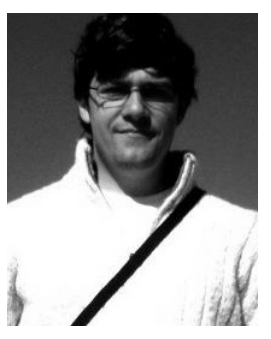

James E. Green (M'15) was born in London, U.K., in 1985. He received the B.Eng., M.Sc., and $\mathrm{Ph} . \mathrm{D}$. degrees in electronic engineering from The University of Sheffield, Sheffield, U.K., in 2006, 2007 , and 2012, respectively.

$\mathrm{He}$ is currently a Lecturer with the Department versity of Sheffield. His current research interests include analog circuits, instrumentation, signal recovery, and power electronic systems and devices, in new materials from baseband to $>50 \mathrm{GHz}$. Apr. 2013, pp. 876-880. of Electronic and Electrical Engineering, The Uni-

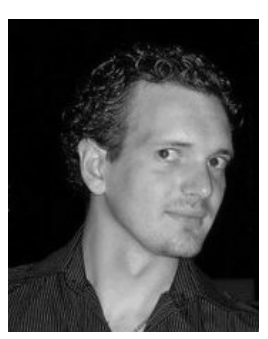

Karlis Zivtins received the B.Eng. degree in electronic systems engineering: computers and networks from the University of Essex, Colchester, U.K., in 2010, and the M.Sc. degree in advanced materials from the University of Surrey, Guildford, U.K., in 2016.

$\mathrm{He}$ is currently a Metallurgy Technician with Intertek, Bristol, U.K.

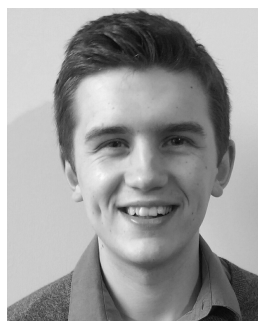

Matthew P. Bower was born in Sheffield, U.K. $\mathrm{He}$ is currently pursuing the M.Eng. degree in aerospace engineering at The University of Sheffield, Sheffield.

$\mathrm{He}$ is currently a Research Assistant at the Advanced Manufacturing Research Centre with Boeing, The University of Sheffield. He is involved in advanced curing technologies with a focus on microwave curing systems.

Richard V. Grainger received the B.Eng. (Hons.) degree in materials engineering from The University of Sheffield, Sheffield, U.K., in 2007, and the Ph.D. degree in resin formulation for the manufacture of self-healing composites for the aerospace industry in 2013.

$\mathrm{He}$ is currently a Materials Engineer with the Engineering and Technology Department, Rolls-Royce plc., East Cowes, U.K. He is involved in materials qualification for the Rolls-Royce CTi composite fan blade, which is a key feature of the next generation of aero engines.

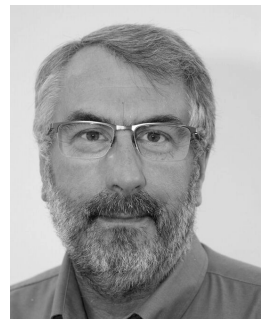

Richard J. Day was born in Bristol, U.K., in 1960. $\mathrm{He}$ received the B.Sc. degree in physics from the Queen Mary University of London, London, U.K., in 1982, the M.Sc. degree in the physics of materials from Bristol University, Bristol, U.K., in 1984, and the $\mathrm{Ph} . \mathrm{D}$. degree in the degradation of polydiacetylene single crystal polymers from the Queen Mary University of London.

He held a Post-Doctoral position with the University of Manchester, Manchester, U.K., where he was a Lecturer and then became a Senior Lecturer and Reader. In 2010, he joined Glyndŵr University, Wrexham, U.K., as a Professor of composites engineering. His current research interests include rapid manufacture of polymer matrix composites, particularly the effect this has on the structure and properties of the material formed.

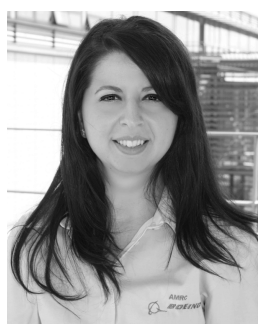

Betime Nuhiji received the B.Eng. (Hons.) degree in mechatronics engineering and $\mathrm{Ph} . \mathrm{D}$. degree in materials engineering from Deakin University, Geelong, VIC, Australia, in 2004 and 2010, respectively. Her Ph.D. research included investigation into how various processing and manufacturing techniques can influence a nanocomposite's structure and properties.

Since 2010, she has been an Enterprise Associate/ Research Technology Manager with The University of Leeds, Leeds, U.K., where her role was to drive strategic research partnerships and academic knowledge transfer between academia and industry. She is currently the Microwave Technology Lead with The University of Sheffield Advanced Manufacturing Research Centre, Catcliffe, U.K., where her area of interest is to steer fundamental research in microwave curing of composite materials to that of industrial implementation.

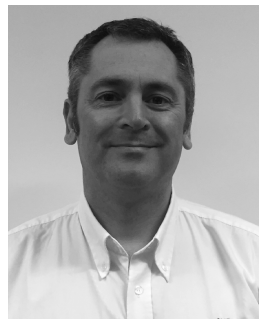

Richard J. Scaife received the B.Eng. (Hons.) degree from Sheffield Hallam University, Sheffield, U.K., in 1987, and the M.Sc. degree from The University of Sheffield, Sheffield, in 1991.

$\mathrm{He}$ became a Chartered Engineer in 1991 as a member of the Institution of Mechanical Engineers. He has worked predominantly in private industry in 2008, he has been leading the Advanced Manufacturing Research Centre (AMRC)-Composites Centre, Catcliffe, U.K., focusing on developing research teams in the areas of machining, advanced cure technologies, automation of layup, dry fiber technology, and the production of metal matrix composites. engineering, management, and director roles. Since 